\title{
Appropriateness of Dabigatran and Rivaroxaban Prescribing for Hospital Inpatients
}

\author{
Unnum Chowdhry, Amanda Jacques, Alan Karovitch, Pierre Giguère, and My-Linh Nguyen
}

\begin{abstract}
Background: Recent approval of the new oral anticoagulants dabigatran and rivaroxaban has led to rapid changes in anticoagulant prescribing practices. Postmarketing reports have highlighted safety concerns with these agents, and their use outside of evidence-based recommendations was noted at the authors' centre.
\end{abstract}

Objectives: To determine the incidence of and risk factors associated with inappropriate prescribing of dabigatran and rivaroxaban.

Methods: This retrospective cohort study investigated randomly selected dabigatran or rivaroxaban prescriptions for patients admitted to a tertiary teaching hospital between January 2010 and December 2012. Appropriateness of prescribing was determined from the documented indication, drug dosage, patient's renal function, and presence of drug interactions, if applicable.

Results: Among a total of 321 medication orders reviewed, the incidence of inappropriate use was $31.2 \%$ (34/109) for dabigatran and $26.9 \%$ (57/212) for rivaroxaban. Of the 97 reasons for inappropriate use that were identified, the most common were prescribing for an unapproved indication (49/97 [50.5\%]), concomitant prescribing of another anticoagulant (22/97 [22.7\%]), and high prescribed dose (9/97 [9.3\%]). The prescribing service was found to be an independent risk factor for inappropriate prescribing $(p=0.041)$. Corrections were made to $23.1 \%$ (21/91) of the incorrect regimens before hospital discharge. In a sensitivity analysis using calculated ideal body weight to estimate renal function, the overall incidence of inappropriate prescribing increased to $31.5 \%$ (101/321).

Conclusions: The proportion of patients with inappropriate prescribing of dabigatran or rivaroxaban in clinical practice was higher than expected. Educational interventions and pharmacy-led initiatives with a focus on appropriate indications, concomitant anticoagulant prescribing, and review of dosage regimens are recommended to improve patient safety.

Keywords: anticoagulants, prescribing patterns, medication safety, dabigatran, rivaroxabans

\section{RÉSUMÉ}

Contexte : La récente approbation de deux nouveaux anticoagulants oraux, le dabigatran et le rivaroxaban, a mené à de rapides changements dans les habitudes de prescription pour l'anticoagulothérapie. Des rapports de pharmacovigilance ont relevé des risques pour la santé relativement à ces agents. De plus, on a noté au centre où travaillent les auteurs que ces médicaments n'étaient pas toujours utilisés selon les recommandations fondées sur des données probantes.

Objectifs : Déterminer quelle est l'incidence des prescriptions inadéquates de dabigatran et de rivaroxaban et quels sont les facteurs de risque qui y sont associés.

Méthodes : La présente étude de cohorte rétrospective a examiné des ordonnances choisies au hasard de dabigatran ou de rivaroxaban, lesquelles étaient destinées à des patients admis dans un hôpital universitaire de soins tertiaires entre janvier 2010 et décembre 2012. La pertinence des prescriptions était établie à l'aide des informations consignées sur l'indication, la posologie, la fonction rénale du patient et la présence d'interactions médicamenteuses, le cas échéant.

Résultats : Parmi l'ensemble des 321 ordonnances analysées, l'incidence d'utilisation inadéquate était de 31,2\% (34/109) pour le dabigatran et de 26,9\% (57/212) pour le rivaroxaban. Des 97 raisons d'utilisation inadéquate qui ont été recensées, les plus fréquentes étaient : la prescription pour une indication non approuvée (49/97 [50,5\%]), la prescription concomitante d'un autre anticoagulant $(22 / 97$ [22,7 \%]) et la prescription d'une dose élevée (9/97 [9,3\%]). Le service auquel appartenait le prescripteur s'est révélé être un facteur de risque indépendant de prescription inadéquate $(p=0.041)$. Des corrections ont été apportées à $23,1 \%$ (21/91) des schémas erronés avant que le congé ne soit donné. Dans une analyse de sensibilité qui s'appuyait sur le calcul du poids idéal pour estimer la fonction rénale, le taux global d'incidence de prescription inadéquate augmentait à 31,5\% (101/321).

Conclusions : La proportion de patients pour qui la prescription de dabigatran ou de rivaroxaban était inadéquate dans la pratique clinique était plus élevée que prévu. Afin d'améliorer la sécurité des patients, on recommande l'adoption d'interventions éducatives et d'initiatives dirigées par les services de pharmacie qui porteront sur les indications adéquates, la prescription concomitante d'anticoagulants et la révision des schémas posologiques.

Mots clés : anticoagulants, habitudes de prescription, sécurité des médicaments, dabigatran, rivaroxaban 


\section{INTRODUCTION}

$T$ he approval of 2 new oral anticoagulants, dabigatran (a direct thrombin inhibitor) and rivaroxaban (a direct factor Xa inhibitor), has quickly led to changes in prescribing practices for anticoagulants. Following studies demonstrating their efficacy and safety, ${ }^{1-11}$ dabigatran and rivaroxaban received Health Canada approval for prevention of venous thromboembolism (VTE) in patients who have undergone elective total hip or knee arthroplasty, prevention of stroke and systemic embolism secondary to atrial fibrillation, and treatment of deep vein thrombosis without symptomatic pulmonary embolism.

The new oral anticoagulant agents offer several advantages over previously available anticoagulants, which have been reflected in the rapid uptake in prescribing, as well as ongoing research evaluating additional uses. ${ }^{7}$ These agents were developed with the aim of maintaining the efficacy and improving on certain limitations associated with warfarin, such as delayed onset of action, narrow therapeutic window, need for routine monitoring of international normalized ratio, frequent dosage adjustments, and numerous dietary and drug interactions. In addition, they have advantages over low-molecular-weight heparins in terms of cost and route of administration. Along with the potential advantages of these new agents come certain limitations that may adversely affect their safety profiles. For example, in cases of suspected drug-induced bleeding, where an estimate of the level of anticoagulant effect may be of value, the lack of a single, specific blood assay to measure the level of anticoagulation is a limitation, as is the lack of availability of a standard and specific reversal agent.

Warfarin has historically been associated with a high number of safety reports to the US Food and Drug Administration (FDA) and has been associated with many adverse events in clinical practice. ${ }^{12-14}$ Despite its recent approval (in 2008), dabigatran surpassed warfarin in terms of the number of postmarketing surveillance reports to the FDA in 2011 and 2012. ${ }^{15,16}$ Because of these safety concerns with dabigatran use, the Institute for Safe Medication Practices Canada considers it an important priority to make the use of anticoagulants, especially dabigatran, safer. ${ }^{17}$ In response to postmarketing reports of serious bleeding events in elderly patients and those with renal impairment, the manufacturer, in consultation with Health Canada, updated the product monograph of dabigatran in 2011, to emphasize the importance of assessing renal function at baseline and at regular intervals during therapy. ${ }^{18} \mathrm{~A}$ small New Zealand audit of bleeding events in patients taking dabigatran, conducted over a 2-month period, identified 44 episodes of bleeding, of which 12 were major. ${ }^{19}$ Other studies have recently examined postmarketing safety concerns with the new oral anticoagulants, including their use in specific situations, such as severe renal impairment. ${ }^{20,21}$ To date, however, no large studies have considered whether rivaroxaban and dabigatran are being used appropriately (i.e., in accordance with current guidelines) in clinical practice.
Use of these agents outside of evidence-based recommendations was noted at the authors' centre. Therefore, the general aim of this study was to analyze the incidence of inappropriate use of dabigatran and rivaroxaban to better identify patients at risk of receiving inappropriate therapy and to aid in the development of targeted educational initiatives to improve patient safety.

The primary objectives were to determine the proportion of cases with inappropriate prescribing of dabigatran or rivaroxaban and to describe the characteristics of these cases.

The secondary objectives were to determine the influence of patient risk factors on the inappropriate use of dabigatran or rivaroxaban, to evaluate trends in inappropriate prescribing over time, and to report the frequency of corrections to initially inappropriate regimens while the patient was still in hospital. The frequency of major bleeding events and thrombotic events occurring in hospital while the patient was taking dabigatran or rivaroxaban was also evaluated. A sensitivity analysis was conducted to reassess the proportion of patients with inappropriate prescribing of dabigatran or rivaroxaban when creatinine clearance $(\mathrm{CrCl})$ was calculated using ideal body weight rather than actual body weight.

\section{METHODS}

\section{Design}

This retrospective cohort study included patients admitted to the University of Ottawa Heart Institute and to the Civic and General campuses of The Ottawa Hospital, a large, multisite, 1117-bed tertiary teaching hospital, between January 1, 2010, and December 31, 2012. The study was conducted with approval from the Ottawa Health Science Network Research Ethics Board.

\section{Patients}

The study population was a randomly generated sample of adult inpatients ( $\geq 18$ years) with a prescription for dabigatran or rivaroxaban as a newly started medication or as a continuation of therapy upon admission to hospital. The cases were identified using the drug utilization report in the hospital pharmacy software. Patients were excluded if body weight had not been documented within 2 years of the admission date or if serum creatinine had not been obtained or recorded before medication administration. For any patients with multiple dabigatran or rivaroxaban orders from different admissions, each admission was considered to be a separate case. However, for patients with multiple admissions included in the study, only the initial patient encounter was used for the collection of demographic information, to prevent duplication of data. Data for a minimum sample of 300 cases was to be obtained using a standardized form. This convenience sample of 300 cases was selected because of time constraints but was deemed to provide a large enough sample size to observe prescribing practice patterns at the study institution. 


\section{Outcomes}

The investigators assessed information from the current Canadian product monographs and relevant literature to determine appropriate prescribing criteria for dabigatran and rivaroxaban, and then adapted these criteria for the purpose of this study (Table 1). The appropriateness of prescribing was evaluated according to these predefined criteria, and prescribing was classified as inappropriate if one or more of the following conditions were met: use of the drug for a condition without an approved indication, prescribed dosage below ("low") or above ("high") prescribing guidelines, inappropriate transition from another anticoagulant, $\mathrm{CrCl}<30 \mathrm{~mL} / \mathrm{min}$, concomitant prescribing and/or use of anticoagulant or thrombolytic (based on review of medication administration record), or potential for interaction with a contraindicated drug.

Consistent with the method used in large clinical trials leading to the approval of dabigatran and rivaroxaban, ${ }^{1-4,9-11,22}$ the
Cockcroft-Gault equation ${ }^{23}$ was used to calculate $\mathrm{CrCl}$ for this study. For the primary analysis, actual body weight was used to calculate $\mathrm{CrCl}\left(\mathrm{CrCl}_{\mathrm{ABW}}\right)$, because the study investigators believed that busy clinicians at the study centre often used a simplified approach based on actual body weight to estimate renal function, rather than determining the $\mathrm{CrCl}$ on the basis of calculated ideal body weight $\left(\mathrm{CrCl}_{\mathrm{IBW}}\right)$. A sensitivity analysis was performed to compare the effect of using $\mathrm{CrCl}_{\mathrm{ABW}}$ and $\mathrm{CrCl}_{\mathrm{IBW}}$ to estimate renal function. Medication dosage was then reassessed on the basis of recalculated $\mathrm{CrCl}_{\mathrm{IBW}}$ for each case to determine prescribing appropriateness. If a patient's height was not available, an estimated typical ideal body weight of $70 \mathrm{~kg}$ for men and $65 \mathrm{~kg}$ for women was used.

A regression analysis was performed to determine possible risk factors associated with inappropriate prescribing. The risk factors in this analysis were ranked, a priori, in order of importance as follows: medication, prescribing service, medication started in hospital or continuation of outpatient regimen, sex,

Table 1. Adapted Criteria for Appropriate Prescribing of Dabigatran and Rivaroxaban ${ }^{7-9,21}$

\begin{tabular}{|c|c|c|c|c|c|}
\hline \multirow[b]{2}{*}{ Criterion } & \multirow[b]{2}{*}{ Patient Factor } & \multirow[b]{2}{*}{$\mathrm{CrCl}(\mathrm{mL} / \mathrm{min})$} & \multicolumn{3}{|c|}{ Indication; Approved Regimen } \\
\hline & & & THA or TKA & $\mathrm{AF}$ & DVT Treatment \\
\hline \multicolumn{6}{|l|}{ Dabigatran } \\
\hline \multirow[t]{3}{*}{ Recommended dose } & Age $<75$ years & $>50$ & 220 mg daily & 110 or $150 \mathrm{mg}$ bid & NA \\
\hline & Age $<75$ years & $30-50$ & 150 mg daily & 110 or 150 mg bid & NA \\
\hline & Age $\geq 75$ years & $>30$ & 150 mg daily & $110 \mathrm{mg}$ bid ( $\geq 80$ years) & NA \\
\hline Renal failure & NA & $<30$ & \multicolumn{2}{|c|}{ Contraindicated } & NA \\
\hline $\begin{array}{l}\text { Interaction, } \\
\text { pharmacodynamic }\end{array}$ & $\begin{array}{l}\text { Anticoagulant or } \\
\text { thrombolytic }\end{array}$ & & \multicolumn{2}{|c|}{ Contraindicated } & NA \\
\hline \multirow[t]{2}{*}{$\begin{array}{l}\text { Transition from } \\
\text { anticoagulant }\end{array}$} & From warfarin & & \multicolumn{2}{|c|}{$\begin{array}{c}\text { Administer after discontinuation } \\
\text { with INR }<2.3\end{array}$} & NA \\
\hline & From SC treatment dose & & \multicolumn{2}{|c|}{$\begin{array}{l}\text { Administer }<2 \mathrm{~h} \text { before } \\
\text { next expected dose }\end{array}$} & NA \\
\hline \multirow[t]{4}{*}{$\begin{array}{l}\text { Interaction, } \\
\text { pharmacokinetic }\end{array}$} & $\begin{array}{l}\text { Ketoconazole, } \\
\text { dronedarone }\end{array}$ & & \multicolumn{2}{|c|}{ Contraindicated } & NA \\
\hline & $\begin{array}{l}\text { Amiodarone, } \\
\text { quinidine }\end{array}$ & & $150 \mathrm{mg}$ daily & Regular dose & NA \\
\hline & Verapamil & $>50$ & 150 mg daily & Regular dose & NA \\
\hline & Verapamil & $30-50$ & 75 mg daily & $150 \mathrm{mg}$ bid & NA \\
\hline \multicolumn{6}{|l|}{ Rivaroxaban } \\
\hline \multirow[t]{2}{*}{ Recommended dose } & & $>50$ & 10 mg daily & 20 mg daily & $\begin{array}{c}15 \mathrm{mg} \text { bid } \\
\times 3 \text { weeks, } \\
\text { then } 20 \text { mg daily }\end{array}$ \\
\hline & & $30-50$ & 10 mg daily & 15 mg daily & $\begin{array}{c}15 \mathrm{mg} \text { bid } \\
\times 3 \text { weeks, } \\
\text { then } 20 \mathrm{mg} \text { daily }\end{array}$ \\
\hline \multicolumn{2}{|l|}{ Renal failure } & $<30$ & $\leftarrow$ & Contraindicated & $\longrightarrow$ \\
\hline $\begin{array}{l}\text { Interaction, } \\
\text { pharmacodynamic }\end{array}$ & $\begin{array}{l}\text { Anticoagulant or } \\
\text { thrombolytic }\end{array}$ & & $\leftarrow$ & Contraindicated & $\longrightarrow$ \\
\hline \multirow{2}{*}{$\begin{array}{l}\text { Transition from } \\
\text { anticoagulant }\end{array}$} & From warfarin & & \multicolumn{3}{|c|}{ Administer after discontinuation with INR $<2.3$} \\
\hline & From SC treatment dose & & \multicolumn{3}{|c|}{ Administer $<2 \mathrm{~h}$ before next expected dose } \\
\hline \multirow[t]{2}{*}{$\begin{array}{l}\text { Interaction, } \\
\text { pharmacokinetic }\end{array}$} & $\begin{array}{l}\text { Ketoconazole, } \\
\text { itraconazole, } \\
\text { voriconazole, } \\
\text { posaconazole }\end{array}$ & & $\leftarrow$ & Contraindicated & $\longrightarrow$ \\
\hline & Ritonavir & & $\leftarrow$ & Contraindicated & 2 \\
\hline
\end{tabular}

$\overline{\mathrm{AF}}=$ atrial fibrillation, $\mathrm{CrCl}=$ creatinine clearance, $\mathrm{DVT}=$ deep vein thrombosis, INR = international normalized ratio, $\mathrm{NA}=$ not applicable, $\mathrm{SC}=$ subcutaneous, THA = total hip arthroplasty, TKA = total knee arthroplasty. 
and age. Prescribing services were grouped as follows: those likely to be prescribing for VTE prophylaxis (orthopedic surgery and short-term rehabilitation), those likely to be prescribing for stroke prophylaxis in atrial fibrillation (medicine, cardiology, and thrombosis), and all other services (other).

The cases included in this study were then evaluated to determine whether major bleeding or thrombotic events had been documented, starting $24 \mathrm{~h}$ after dabigatran or rivaroxaban was initially ordered until either discharge or $48 \mathrm{~h}$ after discontinuation of the medication. Major bleeding events were defined in a manner similar to previous major clinical trials: reduction in hemoglobin of at least $20 \mathrm{~g} / \mathrm{L}$, transfusion of 2 or more units of blood, or bleeding in a critical organ or site (intracranial, intraspinal, intraocular, retroperitoneal). ${ }^{1-6,9-11,24}$ Codes from the International Statistical Classification of Diseases and Related Health Problems, 10th revision (ICD-10), were used to identify cases of bleeding in a critical organ or site, ischemic stroke, systemic embolism, or VTE during the defined study period (for a list of the codes used, see Appendix 1, available at www.cjhp-online.ca/index.php/cjhp/issue/view/115/showToc).

\section{Statistical Analysis}

The results were analyzed with SPSS statistical software, version 13.0 (SPSS Inc, Chicago, Illinois), with a $p$ value of less than 0.05 considered statistically significant. Statistical analysis of bleeding and thrombotic events was to be performed using a $\chi^{2}$ test or the Fisher exact test, if enough events were detected during the study period.

To determine the influence of various risk factors on the inappropriate use of dabigatran and rivaroxaban, a univariate logistic regression model was performed with all predefined variables identified as potential risk factors for inappropriate prescribing. Multivariate logistic regression analysis was then performed using the risk factors found to be significant through univariate analysis. Risk factors associated with inappropriate prescribing were reported as odds ratios.

\section{RESULTS}

Over the data collection period, a total of 1868 cases of dabigatran or rivaroxaban use were identified, of which 335 cases were randomly selected. Ten of these cases were excluded because patient weight was unavailable, and 4 were excluded because no creatinine result was available, leaving 321 cases for the final analysis. Among the cases included in the analysis, there were no patients with multiple prescriptions considered as separate cases.

The baseline characteristics of all cases included in this study are presented in Table 2. Dabigatran was prescribed mainly for prevention of stroke and systemic embolism in patients with atrial fibrillation $(96.3 \%$ [105/109]), whereas rivaroxaban was most commonly used for prevention of VTE in patients undergoing elective hip or knee arthroplasty (75.5\% [160/212]).

\section{Primary Objectives}

Of the 321 anticoagulant prescriptions assessed, 28.3\% (91/321) were considered to be inappropriate according to the criteria set out in Table 1. Prescriptions for dabigatran were deemed inappropriate in $31.2 \%$ (34/109) of cases, and prescriptions for rivaroxaban were deemed inappropriate in $26.9 \%$ (57/212) of cases. Table 3 outlines the different types of inappropriate prescribing observed, with nonapproved usage and concomitant anticoagulant prescribing accounting for $73.2 \%$ (71/97) overall.

Table 2. Baseline Characteristics of Cases Included in the Analysis

\begin{tabular}{|c|c|c|c|}
\hline \multirow[b]{2}{*}{ Characteristic } & \multicolumn{3}{|c|}{ Drug Group; Mean \pm SD* } \\
\hline & $\begin{array}{l}\text { Dabigatran } \\
(n=109)\end{array}$ & $\begin{array}{l}\text { Rivaroxaban } \\
(n=212)\end{array}$ & $\begin{array}{c}\text { Total } \\
(n=321)\end{array}$ \\
\hline Age (years) & $72.7 \pm 12.8$ & $66.0 \pm 13.3$ & $68.0 \pm 13.0$ \\
\hline Sex, male, no. (\%) of patients & $74(67.9)$ & $64(30.2)$ & $138(43.0)$ \\
\hline \multicolumn{4}{|l|}{ Body weight (kg) } \\
\hline Actual & $81.5 \pm 17.7$ & $80.7 \pm 19.9$ & $81.0 \pm 19.2$ \\
\hline Ideal & $66.1 \pm 11.1$ & $58.6 \pm 9.9$ & $61.2 \pm 10.9$ \\
\hline \multicolumn{4}{|l|}{ Creatinine clearance (mL/min) } \\
\hline $\mathrm{CrCl}_{\mathrm{ABW}}$ & $84.5 \pm 49.1$ & $103.0 \pm 49.7$ & $96.7 \pm 50.2$ \\
\hline $\mathrm{CrCl}_{\mathrm{BBW}}$ & $60.9 \pm 29.8$ & $71.3 \pm 32.4$ & $67.8 \pm 31.9$ \\
\hline Length of stay (days), median (range) & $6(0-77)$ & $12(0-164)$ & $10(0-164)$ \\
\hline \multicolumn{4}{|l|}{ Prescribing service, no. (\%) of patients } \\
\hline Orthopedics, short-term rehabilitation & $4(3.7)$ & $197(92.9)$ & $201(62.6)$ \\
\hline Medicine, cardiology, thrombosis & $70(64.2)$ & $8(3.8)$ & $78(24.3)$ \\
\hline Other & $35(32.1)$ & $7 \quad(3.3)$ & $42(13.1)$ \\
\hline $\begin{array}{l}\text { Use of ASA, NSAID, or antiplatelet } \\
\text { agent, no. }(\%)\end{array}$ & $45(41.3)$ & $163(76.9)$ & $208(64.8)$ \\
\hline $\begin{array}{l}\text { ASA = acetylsalicylic acid, } \mathrm{CrCl}_{\mathrm{ABW}}=\mathrm{C} \\
\mathrm{CrCl} \mathrm{IBW}_{\text {IB }}=\text { creatinine clearance using ic } \\
\text { anti-inflammatory drug, } \mathrm{SD}=\text { standar } \\
{ }^{*} \text { Except where indicated otherwise. }\end{array}$ & $\begin{array}{l}\text { ine cleara } \\
\text { ody weigh } \\
\text { iation. }\end{array}$ & $\begin{array}{l}\text { actual body } \\
=\text { nonsteroic }\end{array}$ & \\
\hline
\end{tabular}


This single copy is for your personal, non-commercial use only.

For permission to reprint multiple copies or to order presentation-ready copies for distribution, contact CJHP at cjhpedit@cshp.ca

Table 3. Characteristics of Inappropriate Prescriptions

\begin{tabular}{|c|c|c|c|}
\hline \multirow[b]{2}{*}{ Characteristic } & \multicolumn{3}{|c|}{ Drug Group; No. (\%) of Reasons* } \\
\hline & $\begin{array}{c}\text { Dabigatran } \\
(n=39)\end{array}$ & $\begin{array}{l}\text { Rivaroxaban } \\
\quad(n=58)\end{array}$ & $\begin{array}{c}\text { Total } \\
(n=97)\end{array}$ \\
\hline Nonapproved use & $4(10)$ & $45(78)$ & $49(50.5)$ \\
\hline Hip resurfacing or knee debridement & $0 \quad(0)$ & $13(22)$ & $13(13.4)$ \\
\hline Hip fracture & $0 \quad(0)$ & $10(17)$ & $10(10.3)$ \\
\hline Other fracture & $0 \quad(0)$ & $11(19)$ & $11(11.3)$ \\
\hline Orthopedic use without fracture & $0 \quad(0)$ & $5 \quad(9)$ & $5 \quad(5.2)$ \\
\hline Pulmonary embolism & $0 \quad(0)$ & $2+(3)$ & $2+(2.1)$ \\
\hline Bioprosthetic heart valve & $2(5)$ & $0 \quad(0)$ & $2(2.1)$ \\
\hline DVT treatment & 1 (3) & $0 \quad(0)$ & $1(1.0)$ \\
\hline DVT prophylaxis (no THA or TKA) & 1 (3) & $0 \quad(0)$ & 1 (1.0) \\
\hline Other & $0 \quad(0)$ & $4(7)$ & $4(4.1)$ \\
\hline \multicolumn{4}{|l|}{$\overline{\text { Concomitant anticoagulant }}$} \\
\hline Prescribed but not administered & $11(28)$ & $6(10)$ & $17(17.5)$ \\
\hline Prescribed and administered & $2(5)$ & $3(5)$ & $5 \quad(5.2)$ \\
\hline $\begin{array}{l}\text { Inappropriate transition } \\
\text { from anticoagulant }\end{array}$ & $7(18)$ & $0 \quad(0)$ & $7 \quad(7.2)$ \\
\hline Dose high & $8(21)$ & $1(2)$ & $9 \quad(9.3)$ \\
\hline Dose low & $4(10)$ & $\begin{array}{ll}0 & (0) \\
\end{array}$ & $4 \quad(4.1)$ \\
\hline Renal failure & $2(5)$ & $3(5)$ & $5 \quad(5.2)$ \\
\hline Contraindicated drug interaction & $1 \quad(3)$ & $0 \quad(0)$ & $1(1.0)$ \\
\hline \multicolumn{4}{|c|}{$\begin{array}{l}\text { DVT = deep vein thrombosis, THA = total hip arthroplasty, TKA = total knee arthroplasty. } \\
\text { *Overall, } 97 \text { reasons for inappropriate prescribing were identified among a total of } \\
91 \text { prescriptions that were classified as inappropriate (some prescriptions were inappropriate } \\
\text { for more than one reason). } \\
\text { tAt the time of data collection, rivaroxaban was not approved for treatment of pulmonary } \\
\text { embolism (it was approved later, in } 2013 \text { ); therefore, although these } 2 \text { cases occurred after } \\
\text { the release of the EINSTEIN-PE study results }{ }^{25} \text { but before Health Canada approval, they } \\
\text { were classified as nonapproved usage. }\end{array}$} \\
\hline
\end{tabular}

\section{Secondary Objectives}

In the univariate logistic regression model, the risk factors of prescribing service and male sex were significantly associated with inappropriate prescribing (see Appendix 2, available at www.cjhp-online.ca/index.php/cjhp/issue/view/115/showToc). In the multivariate logistic regression with these variables, only the group of prescribing services classified as "other" maintained an association with inappropriate use (odds ratio 2.09, $p=0.041$ ). Figure 1 shows the number of inappropriate prescriptions and overall prescribing trends for dabigatran and rivaroxaban over the study period. For $23.1 \%$ (21/91) of the inappropriate prescriptions, correction of the prescription before hospital discharge was documented: this applied to 18 (53\%) of the 34 inappropriate prescriptions for dabigatran but only $3(5 \%)$ of the 57 inappropriate prescriptions for rivaroxaban.

Of the 321 cases included in this study, 19 had a reduction in hemoglobin, 19 required blood transfusions, and 4 had documentation of both a reduction in hemoglobin and requirement for blood transfusion. The rates were similar for those with appropriate and inappropriate prescribing of the novel oral anticoagulants. There were no documented cases of thrombotic events or bleeding in a critical organ or site. No statistical comparisons were performed using these data, because the rate of documented adverse safety events was very low.

\section{Sensitivity Analysis}

When $\mathrm{CrCl}_{\mathrm{IBW}}$, rather than $\mathrm{CrCl}_{\mathrm{ABW}}$, was used to estimate renal function, there was one additional case of rivaroxaban prescribed at a too-high dose and 11 additional cases (7 for rivaroxaban, 4 for dabigatran) in which the recalculated $\mathrm{CrCl}_{\mathrm{IBW}}$ dropped below $30 \mathrm{~mL} / \mathrm{min}$. More specifically, the average $\mathrm{CrCl}$ for these 11 patients decreased from $38.3 \mathrm{~mL} / \mathrm{min}$ to $26.3 \mathrm{~mL} / \mathrm{min}$ when recalculated using ideal body weight. Overall, this sensitivity analysis increased the number of reasons for inappropriate prescribing from 97 to 109 . Because some prescriptions were inappropriate for multiple reasons, the overall change in the total number of inappropriate prescriptions was an increase from $91 / 321(28.3 \%)$ to $101 / 321(31.5 \%)$.

\section{DISCUSSION}

In this 3-year retrospective study of 321 randomly selected cases, there were almost twice as many prescriptions for rivaroxaban as for dabigatran (212 versus 109). The demographic characteristics of patients for whom dabigatran or rivaroxaban was prescribed were similar. The observed differences with respect to sex, concomitant use of other medications (specifically acetylsalicylic acid, nonsteroidal anti-inflammatory drugs, or antiplatelet agents), and prescribing service were likely related to the most common patient groups for which these medications were used at the study centre. 


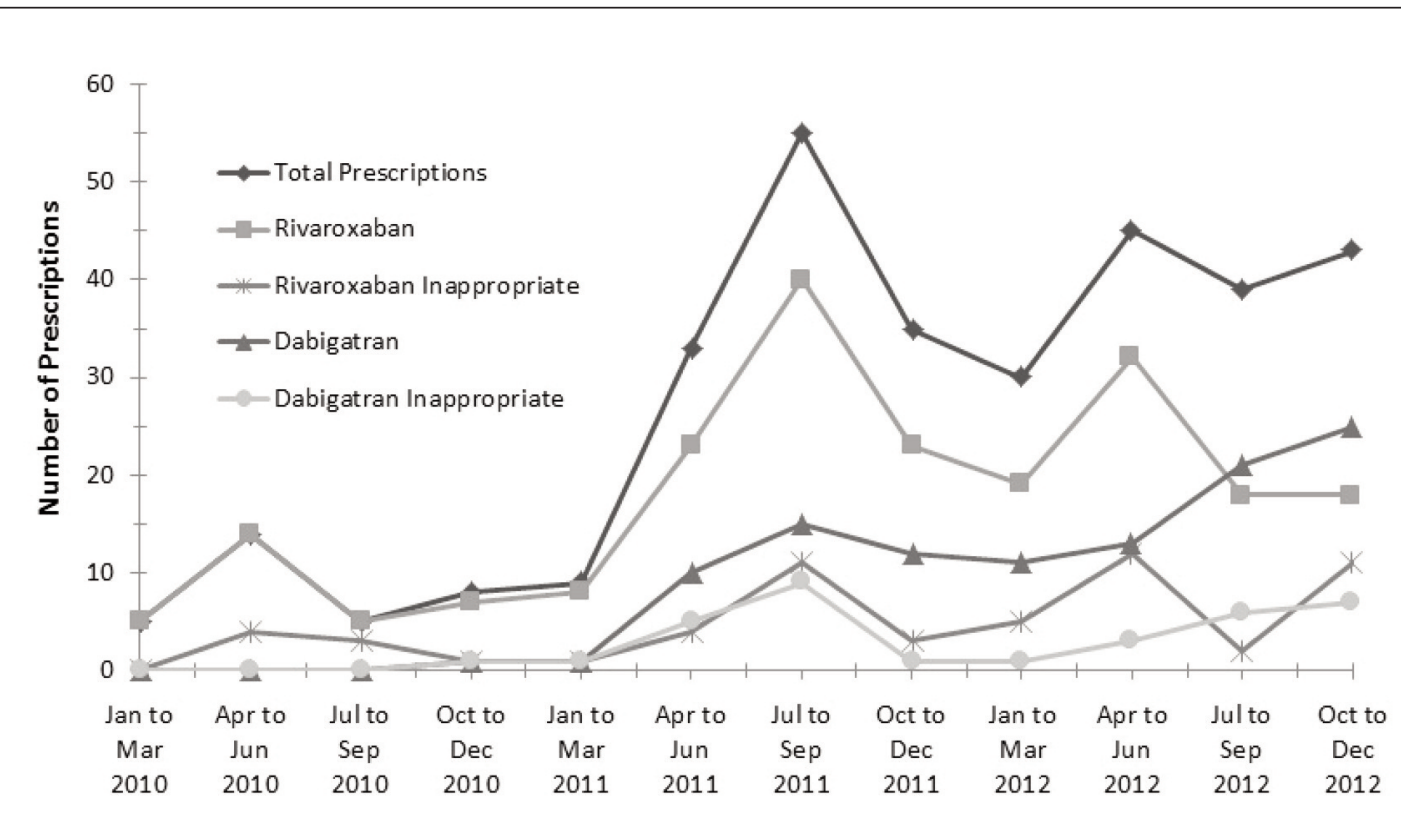

Figure 1. Inappropriate and overall prescribing trends for dabigatran and rivaroxaban over the study period.

Concomitant prescribing of the new oral agents with an additional anticoagulant was often the reason for inappropriate prescribing. In a number of cases, heparin or low-molecular weight heparin was ordered for a patient at the time of admission, and continuation of preadmission dabigatran was also ordered. This resulted in simultaneous anticoagulant prescribing while the patient was in hospital (although simultaneous prescribing was often noticed and addressed before administration of multiple anticoagulants to the patient). Patients with atrial fibrillation who are admitted to hospital often have additional indications for anticoagulation, such as VTE (prophylaxis or treatment) or myocardial infarction, and it is therefore imperative that home medications be reconciled in hospital before additional anticoagulant agents are initiated. Simultaneous prescription of rivaroxaban with other anticoagulants was less frequent, a finding that may have been related to the prescreening process in the surgical preadmission unit or greater familiarity with and use of this agent in the orthopedic setting. Given these findings, systems should be put in place to ensure that whenever dabigatran or rivaroxaban is being initiated or restarted in hospital, the patient's physician and pharmacist perform a medication review.

All 8 cases of high-dose dabigatran were related to a lack of dose reduction as recommended for patients 75 years of age or older. The substantially lower rate of inappropriately high dosing of rivaroxaban may be explained by the fact that rivaroxaban for the indication of VTE prophylaxis does not require any dose reduction for age, whereas dabigatran in the setting of atrial fibrillation does require a dose reduction for older patients.

Nonapproved indications accounted for a majority of cases (45/58 [78\%]) of inappropriate use of rivaroxaban. Use of this drug has not been adequately studied in clinical trials, except in the setting of elective total hip and knee arthroplasty. Until the efficacy and safety of rivaroxaban has been studied in other orthopedic patient populations, its use should be discouraged and discussed with prescribers. Notably, rivaroxaban received Health Canada approval for prevention of stroke and systemic embolism secondary to atrial fibrillation in January 2012 and for treatment of deep vein thrombosis without symptomatic pulmonary embolism in February 2012. Both of these approval dates occurred within the data collection period for this study.

The significantly greater risk of inappropriate prescribing by prescribing services classified as "other" suggests that more specialized services, which presumably had more experience with dabigatran and/or rivaroxaban, were more likely to correctly follow the guidelines for use of these drugs. A total of 16 services were included as "other prescribing services", of which neurology, neurosurgery, and cardiac surgery had the highest prescribing rates. Targeted educational interventions for these services may be one method of reducing inappropriate use of these agents, along with reinforcing the option to consult specialty services in more complicated or unclear cases in which the use of oral anticoagulants is being considered.

Over the 3-year study period, the ratio of inappropriate to total prescribing of each agent remained relatively constant. The high incidence of inappropriate and overall prescribing of rivaroxaban in 2012 occurred in the few months following Health Canada approval for the additional indications of atrial fibrillation and treatment of deep vein thrombosis. The increase in inappropriate and overall prescribing of dabigatran in 2011 occurred following addition of this drug to the hospital formulary. 
Of the 21 inappropriate prescriptions that were corrected before hospital discharge, only 3 were for rivaroxaban. The low number of corrections for this drug may be related to the high proportion of its inappropriate prescriptions that were for nonapproved indications, a factor that is difficult to identify through prescription review. Some orders for rivaroxaban may have represented intentional off-label use in areas not yet adequately studied in clinical trials, such as hip fracture.

There are both advantages and limitations to using either actual or ideal body weight in the Cockcroft-Gault equation, and the current literature does not provide a clear consensus as to which method is preferable. ${ }^{26}$ In the 11 cases where the $\mathrm{CrCl}$ dropped to below $30 \mathrm{~mL} / \mathrm{min}$ when ideal body weight was used, initiation of the anticoagulant was reclassified from potentially appropriate to inappropriate. The decrease in $\mathrm{CrCl}$ with a different method of calculation can be explained by the potential for actual body weight to overestimate renal function in overweight patients. It is therefore likely that these patients had substantial renal impairment and that many of them would have been at higher risk for accumulation of the drug and potential bleeding events. To improve patient safety, we suggest that practitioners keep in mind the potential for $\mathrm{CrCl}_{\mathrm{ABW}}$ to overestimate renal function in overweight patients.

An audit of bleeding events in patients receiving dabigatran was conducted in New Zealand, in response to concerns from hematologists. ${ }^{19}$ Forty-four episodes of bleeding were identified in a 2-month period, of which 12 were categorized as major. The top 3 factors contributing to bleeding that were identified in this audit (prescriber error, impaired renal function, patient age) ${ }^{19}$ were also identified as contributing factors to inappropriate dosing of dabigatran and rivaroxaban in the current study.

The method of assessing the appropriateness of prescribing may have implications for the generalizability of this study. Appropriateness was evaluated, on the basis of the criteria in Table 1, at the time of initial prescribing; any subsequent changes in clinical status were not recorded, and appropriateness was not reassessed at any time after initial prescribing. Individual patient factors that were not considered because of a lack of standardized recommendations and limited data collection time included the presence of liver dysfunction and the estimated stroke risk secondary to atrial fibrillation. The duration of anticoagulation use and patient adherence with therapy were also not considered in the assessment of appropriateness, because of the difficulty of collecting such information after patient discharge. The relatively small sample size and short length of stay in most cases were limiting factors in the identification of both bleeding and thrombotic events. Readmissions due to bleeding events for patients who were receiving dabigatran or rivaroxaban outside of the study hospital were also not assessed. Further limitations inherent to the design of this retrospective study relate to the accuracy and completeness of relevant information in each patient's electronic medical record, the inclusion of bleeding and thrombotic events only if coded by the appropriate ICD-10 code, and the possibility of other factors confounding observed hemoglobin reductions or need for blood transfusions.

We suggest that educational initiatives to address the use of new oral anticoagulants should highlight appropriate indications and the importance of avoiding concomitant prescribing of other anticoagulants. Tools to reinforce the main areas that require continued education could include pocket cards or electronic summary documents outlining the major indications, contraindications, and dosing adjustments for each agent; an electronic tool to calculate a patient's estimated $\mathrm{CrCrl}$ and suggested oral anticoagulant dosing; a process that would alert the prescriber when the home medications of a newly admitted patient include an anticoagulant; and intensive educational interventions and/or academic detailing followed by a second study to assess the impact of these initiatives.

\section{CONCLUSION}

The proportion of patients with an inappropriate prescription for dabigatran or rivaroxaban was higher than expected at the study centre. Inappropriate prescriptions for rivaroxaban were mainly due to use of this drug for an unapproved indication. Inappropriate dabigatran usage was mainly due to prescribing with a concomitant anticoagulant and incorrect dosing regimens. Pharmacy-led initiatives and educational interventions, with priority given to the main factors identified as being associated with inappropriate use, are recommended at the study centre to improve the safe use of these new anticoagulants and to prevent possible patient harm.

\section{References}

1. Eriksson BI, Borris LC, Friedman RJ, Haas S, Huisman MV, Kakkar AK, et al.; RECORD1 Study Group. Rivaroxaban versus enoxaparin for thromboprophylaxis after hip arthroplasty. $N$ Engl J Med. 2008;358(26):2765-75.

2. Lassen MR, Ageno W, Borris LC, Lieberman JR, Rosencher N, Bandel TJ, et al.; RECORD3 Investigators. Rivaroxaban versus enoxaparin for thromboprophylaxis after total knee arthroplasty. N Engl J Med. 2008;358(26): 2776-86.

3. Kakkar AK, Brenner B, Dahl OE, Eriksson BI, Mouret P, Muntz J, et al.; RECORD2 Investigators. Extended duration rivaroxaban versus short-term enoxaparin for the prevention of venous thromboembolism after total hip arthroplasty: a double-blind, randomised controlled trial. Lancet. 2008; 372(9632):31-9.

4. Turpie AG, Lassen MR, Davidson BL, Bauer KA, Gent M, Kwong LM, et al.; RECORD4 Investigators. Rivaroxaban versus enoxaparin for thromboprophylaxis after total knee arthroplasty (RECORD4): a randomised trial. Lancet. 2009;373(9676):1673-80.

5. Eriksson BI, Dahl OE, Rosencher N, Kurth AA, van Dijk CN, Frostick SP, et al.; RE-MODEL Study Group. Oral dabigatran etexilate vs. subcutaneous enoxaparin for the prevention of venous thromboembolism after total knee replacement: the RE-MODEL randomized trial. J Thromb Haemost. 2007;5(11):2178-85.

6. Eriksson BI, Dahl OE, Huo MH, Kurth AA, Hantel S, Hermansson K, et al.; RE-NOVATE II Study Group. Oral dabigatran versus enoxaparin for thromboprophylaxis after primary total hip arthroplasty (RE-NOVATE II*). A randomised, double-blind, non-inferiority trial. Thromb Haemost. 2011; 105(4):721-9. 
7. XARELTO (rivaroxaban) [product monograph]. Toronto (ON): Bayer Inc; 2012 Jul 18

8. PRADAXA (dabigatran) [product monograph]. Burlington (ON): Boehringer Ingelheim Canada Ltd; 2012 Sep 5.

9. Connolly SJ, Ezekowitz MD, Yusuf S, Eikelboom J, Oldgren J, Parekh A, et al.; RE-LY Steering Committee and Investigators. Dabigatran versus warfarin in patients with atrial fibrillation. N Engl J Med. 2009;361(12):1139-51.

10. Patel MR, Mahaffey KW, Garg J, Pan G, Singer DE, Hacke W, et al.; ROCKET AF Investigators. Rivaroxaban versus warfarin in nonvalvular atrial fibrillation. N EnglJ Med. 2011;365(10):883-91.

11. EINSTEIN Investigators, Bauersachs R, Berkowitz SD, Brenner B, Buller HR, Decousus H, Gallus AS, et al. Oral rivaroxaban for symptomatic venous thromboembolism. N Engl J Med. 2010;363(26):2499-510.

12. Lee A, Crowther M. Practical issues with vitamin $\mathrm{K}$ antagonists: elevated INRs, low time-in-therapeutic range, and warfarin failure. $J$ Thromb Thrombolysis. 2011;31(3):249-58.

13. Hylek EM, Evans-Molina C, Shea C, Henault LE, Regan S. Major hemorrhage and tolerability of warfarin in the first year of therapy among elderly patients with atrial fibrillation. Circulation. 2007;115(21):2689-96.

14. McMahan DA, Smith DM, Carey MA, Zhou XH. Risk of major hemorrhage for outpatients treated with warfarin. J Gen Intern Med. 1998; 13(5):311-6.

15. Moore TJ, Furberg CD, Cohen MR. Anticoagulants the leading reported drug risk in 2011. New data from 2011 quarters 3 - 4. QuarterWatch. 2011;Q4:1-25. Published by Institute for Safe Medication Practices (Horsham, PA).

16. Moore, TJ, Cohen MR, Furberg CD, Mattison DR. Leading drug safety issues of 2012. QuarterWatch. 2012;Q4:1-21. Published by Institute for Safe Medication Practices (Horsham, PA).

17. Top 10 drugs reported as causing harm through medication error. ISMP Can Saf Bull. 2006;6(1):1-2.

18. Knecht M. Health Canada endorsed important safety information on Pradaxa $^{\mathrm{TM}} /$ Pradax® (dabigatran etexilate). Burlington $(\mathrm{ON})$ : Boehringer Ingelheim Canada Ltd; 2012 Dec 21. Available from: www.boehringeringelheim.ca/content/dam/internet/opu/ca_EN/documents/humanhealth/ 121221-hpc-final-dated-Dec-21.pdf

19. Harper P, Young L, Merriman E. Bleeding risk with dabigatran in the frail elderly. N Engl J Med. 2012;366(9):864-6.

20. Mack DR, Kim JJ. Pharmacokinetic and clinical implications of dabigatran use in severe renal impairment for stroke prevention in nonvalvular atrial fibrillation. Ann Pharmacother. 2012;46(7-8):1105-10.

21. Freshour JE, Hudson JQ, Stevens AB, Franks AS. Epistaxis associated with dabigatran in an elderly patient with reduced creatinine clearance. Am J Health Syst Pharm. 2012;69(14):1184-6.
22. Ezekowitz MD, Connolly S, Parekh A, Reilly PA, Varrone J, Wang S, et al. Rationale and design of RE-LY: randomized evaluation of long-term anticoagulation therapy, warfarin, compared with dabigatran. Am Heart J. 2009; 157(5):805-10.

23. Cockcroft DW, Gault MH. Prediction of creatinine clearance from serum creatinine. Nephron. 1976;16(1):31-41.

24. Falck-Ytter Y, Francis CW, Johanson NA, Curley C, Dahl OE, Schulman S, et al. Prevention of VTE in orthopedic surgery patients: antithrombotic therapy and prevention of thrombosis, 9th ed: American College of Chest Physicians evidence-based clinical practice guidelines. Chest. 2012;141 (2 Suppl):e278S-325S.

25. EINSTEIN-PE Investigators, Büller HR, Prins MH, Lensin AW, Decousus $\mathrm{H}$, Jacobson BF, Minar E, et al. Oral rivaroxaban for the treatment of symptomatic pulmonary embolism. $N$ Engl J Med. 2012;366(14):1287-97.

26. Winter MA, Guhr KN, Berg GM. Impact of various body weight and serum creatinine concentrations on the bias and accuracy of the Cockcroft-Gault equation. Pharmacotherapy. 2012;32(7):604-12.

Unnum Chowdhry, BScPhm, is a Pharmacist with Northwest Telepharmacy Solutions, Ottawa, Ontario.

Amanda Jacques, BSCPhm, ACPR, is a Pharmacist with The Ottawa Hospital, Ottawa, Ontario.

Alan Karovitch, MD, MEd, FRCPC, is a Physician with The Ottawa Hospital, Ottawa, Ontario.

Pierre Giguère, BPhm, MSc, is a Pharmacist with The Ottawa Hospital, Ottawa, Ontario.

My-Linh Nguyen, BScPhm, ACPR, is a Pharmacist with The Ottawa Hospital, Ottawa, Ontario.

Competing interests: None declared.

Address correspondence to:

Unnum Chowdhry

Northwest Telepharmacy Solutions

19 Stone Park Lane

Ottawa ON K2H 9P4

e-mail: uchowdhry@northwest.ca

Funding: None received. 